\title{
MICROSTRUCTURE OF INTERFACIAL TRANSITION ZONE BETWEEN PET FIBRES AND CEMENT PASTE
}

\section{Vladimír MACHOVIČ ${ }^{1,2) *}$, Ladislav LAPČÁK ${ }^{1)}$, Lenka BORECKÁ ${ }^{2)}$, Miloslav LHOTKA ${ }^{1)}$, Jana ANDERTOVÁ ${ }^{1)}$, Lubomír KOPECKÝ ${ }^{3)}$ and Linda MIŠKOVÁ ${ }^{1)}$}

\author{
${ }^{1)}$ Institute of Chemical Technology Prague, Technická 5, 166 28, Prague, Czech Republic \\ 2) Institute of Rock Structure and Mechanics v.v.i., ASCR, V Holešovičkách 41, 18209 Prague, Czech Republic \\ ${ }^{3)}$ Czech Technical University in Prague, Faculty of Civil Engineering, Thákurova 7, 16629 Prague, Czech \\ Republic \\ *Corresponding author's e-mail: machoviv@vscht.cz
}

(Received November 2012, accepted January 2013)

\begin{abstract}
Considerable amount of waste in the form of polyethylene terephthalate (PET) bottles could be utilized in the form of dispersed microreinforcement in concrete. PET fibres, however, have poor wettability and adhesion to cement paste, which can be modified by alkaline hydrolysis with sodium hydroxide at elevated temperature. The alkaline treatment was used to increase fibre surface, which was followed by changes in the structure of the interfacial transition zone (ITZ) and interfacial bond between fibre and cementitious matrix. Raman microspectroscopy mapping was employed to study microstructural changes of ITZ within the distance $0-250 \mu \mathrm{m}$ from a PET fibre. The band at $357 \mathrm{~cm}^{-1}$ corresponding to the $\mathrm{Ca}-\mathrm{O}$ bond vibration in portlandite was used to determine its distribution. For determination of the relative abundance of ettringite, the $\mathrm{SO}_{4}{ }^{2-}$ stretching vibration at $987 \mathrm{~cm}^{-1}$ was used. The most intensive bands of portlandite and ettringite were found within the distance $0-50 \mu \mathrm{m}$ from an unmodified PET fibre. Besides the elevated concentration of these minerals, abundant pores occur in this region. In the case of alkaline modified PET fibres the ITZ zone was not found.
\end{abstract}

KEYWORDS: fibre reinforced concrete, PET, Raman mapping microspectroscopy

\section{INTRODUCTION}

Increasing amount of waste in the form of polyethylene terephthalate (PET) bottles has become a problem worldwide. That is why a search for useful and meaningful utilization of this waste should be commenced. One of the promising ways to utilization of the PET waste is its use in the form of dispersed microreinforcement in concrete. Concrete is one of the most frequently used construction materials. It is a relatively brittle material with a low tensile strength. The tensile strength in concrete has thus to be increased by means of conventional steel reinforcement or by addition of fibres from steel, glass, carbon or polymeric materials. Fibre reinforcement is an effective way of improving strength, ductility, and toughness of the brittle cementitious material (Zollo, 1997). Quality of resulting composites is given by properties of the cementitious matrix, material of fibres, their content, surface, shape, and adhesion to the cementitious matrix.

Concrete is considered as a three component composite material consisting of cementitious matrix, aggregates, and the so called interfacial transition zone (ITZ) (Ollivier et al., 1995; Chan and Li, 1997; Scrivener, 2004; Scrivener et al., 2004). Microstructure of ITZ between aggregates (gravel or sand particles, or fibres) and the bulk cementitious matrix is a critical point determining final strength of the concrete composite. Formation of ITZ is caused by the so called "wall-effect", in which packing of small cement grains around a fibre or an aggregate particle takes place. During mixing of concrete and before its setting, microbleeding leads to accumulation of water under the aggregate particles. In the area of ITZ, an increased porosity can be observed due to these processes, as well as a higher ratio of water to the cementitious paste $(\mathrm{w} / \mathrm{c})$ compared to the cementitious matrix within a longer distance from an aggregate particle or fibre (Ollivier et al., 1995; Chan and Li, 1997; Scrivener, 2004; Scrivener et al., 2004). According to numerous studies, the ITZ thickness ranges from 15 to 50 micrometres. ITZ has, as found in nanoindentation measurements, much lower strength compared to the "bulk" matrix. Inside large pores, ITZ contains predominantly large crystals of portlandite $\mathrm{Ca}(\mathrm{OH})_{2}$ and needle shaped crystals of ettringite. In this area also a lower relative abundance of non-hydrated minerals, e.g., alite $\left(\mathrm{C}_{3} \mathrm{~S}\right.$, in the cement chemist notation, CCN), were found (Ollivier et al., 1995).

Microstructural analysis has shown that physicochemical bonds predominate between polypropylene fibres and the cementitious matrix. The bond depends on the temperature of hydration of the cementitious matrix, composition of solutions within 
the matrix pores, and on the way of mixing. These parameters can significantly alter the surface morphology of a polymer fibre, and thus also its surface area. The ITZ microstructure is altered this way and the bond between fibres and the cementitious matrix strengthened (Tagnit-Hamon et al., 2005). Polymer fibres have some unfavourable properties as poor adhesion and wettability. That is why it is necessary to maximize the strength of the interfacial bond to increase firmness of the composite. For this purpose, fibre deformation (e.g., fibrillation), surface modification of fibres by chemical treatment (e.g., alkaline hydrolysis), or plasma modification is used, in which polar functional groups are formed on the fibre surface. Densification of ITZ by finely ground inorganic materials (e.g., silica fume) is used (Chan and $\mathrm{Li}, 1997$ ).

The microstructure of ITZ was studied mainly using the environmental scanning electron microscopy (ESEM) (Scrivener, 2004; Scrivener et al., 2004) and nanoindentation (e.g. Ollivier et al., 1995; Machovič et al., 2008a).

In the cement chemistry, Raman spectroscopic analysis has traditionally been a laboratory tool for structural analysis of cement clinkers and hydration products (Deng et al., 2002; Potgieter-Vermaak et al., 2006; Gastaldi et al., 2007; Pešková et al., 2011). Recent developments in the instrumentation make it possible to use Raman spectroscopy as a tool for identification of cement phases including different polymorphic and crystalline forms, investigation of cement hydration, admixtures, concrete-polymer and alkali-aggregate reactions, and concrete carbonation. In our laboratory, the ITZ between PET fibres and cementitious matrix was studied also by means of Raman microspectroscopy mapping (Machovič et al., 2008a).

The present study follows the previous one and has been aimed at modification of the PET fibre surface by alkaline hydrolysis with sodium hydroxide at an elevated temperature, which should via changes in physicochemical properties of the fibre increase the strength of binding between the fibre and cementitious matrix. These changes were detected by changes in the mineralogical composition and morphology of ITZ and the surrounding cementitious matrix studied by means of Raman microspectroscopy mapping and environmental scanning electron microscopy (ESEM). The surface modification of PET fibres could alter the ITZ microstructure and thus positively process cohesive properties of the cementitious matrix in relation to PET fibres.

\section{EXPERIMENTAL}

Samples were prepared only from a cement paste without sand or gravel aggregate to enable detection of minimum effect of the modified PET fibres on the composite. The samples were prepared by mixing ordinary Portland cement with water $(\mathrm{w} / \mathrm{c}=0.4)$ and PET fibres $(2 \mathrm{wt} \%)$. The fibres are produced in a fac- tory (Spokar, a.s. Pelhřimov) that recycles PET bottles. The fibres were added to the concrete mixture as monofilaments with a diameter of $290 \mu \mathrm{m}$ and length of about $10 \mathrm{~mm}$. The alkaline hydrolysis of the PET fibres was achieved by $1 \mathrm{M} \mathrm{NaOH}$ solution. The fibres were soaked in the solution, initially heated to $90{ }^{\circ} \mathrm{C}$ at a heating rate of $10^{\circ} \mathrm{C}$ per minute, and then left at an ambient temperature for three days. The fibres were washed with distilled water after the hydrolysis. The alkaline hydrolysed fibre samples were denoted as PET-NaOH. Reference fibres were treated only by heating in distilled water at the same heating rate as the PET-NaOH fibres, and denoted as $\mathrm{PET}-\mathrm{H}_{2} \mathrm{O}$. After hydration for 50 days (desiccator $100 \%$ humidity), hardened cement/PET samples were cut and their surface polished.

The environmental scanning electron microscope - XL30 ESEM FEI PHILIPS - was equipped with a set of electron detectors: SED (GSED) for micromorphology, and BSED (GBSED) for phase contrast both in high vacuum and environmental modes.

Raman spectra were collected using a Thermo Scientific model DXR microscope equipped with a $532 \mathrm{~nm}$ line laser for excitation of cementitious materials. Locations of interest were positioned using a motorized XY stage and an optical camera. The spot size of the laser focused by the 10x objective was $3.1 \mu \mathrm{m}$ in diameter on the sample. The laser power and the time of sample excitation were adjusted to obtain high quality Raman spectra allowing creation of spectral maps. The scattered light was analysed by a spectrograph with holographic grating (900 gr. per $\mathrm{mm}$ ) and slit width $50 \mu \mathrm{m}$. The acquisition time was $10 \mathrm{~s}$. Ten accumulations were co-added to obtain a spectrum. A $10 \mu \mathrm{m}$ step was selected for microspectroscopic line mapping using the OMNIC Atlus imaging software program (ThermoFisher Scientific, Inc., MA, USA).

Adsorption isotherms of $\mathrm{N}_{2}$ were determined for the samples of cement composites and used for calculation of the specific surface of mesopores by the BET method. These measurements were carried out using a multipurpose instruments ASAP 2020 or ASAP 2050 by Micromeritic, with nitrogen gas at the temperature of liquid nitrogen. An intrusion-extrusion curve was constructed for porosity determination. The measurement was carried out using a mercury porosimeter AutoPore IV 9500 by Micromeritic. The determination was split to a low and a high pressure parts, with measurement in the macropore and mesopore region within the pressure range $0.03 \mathrm{MPa}$ to $400 \mathrm{MPa}$, i.e., for pore radii ranging from $2 \cdot 10^{-5}$ to $1.5 \cdot 10^{-9} \mathrm{~m}$.

\section{RESULTS AND DISCUSSION}

During the alkaline hydrolysis of PET fibres with sodium hydroxide at an elevated temperature, morphological changes occur on the fibre surface. Their surface increases as well as the relative 

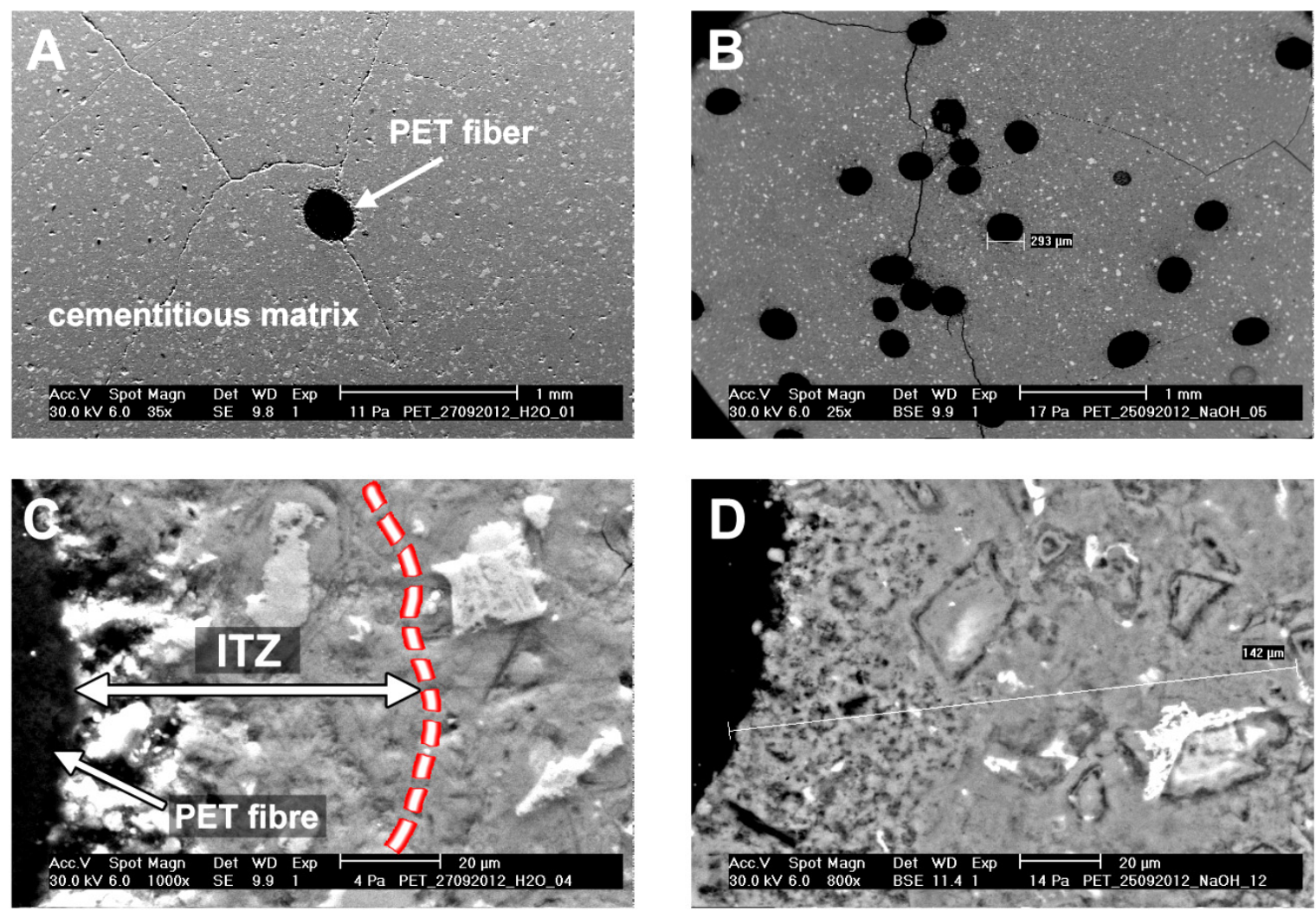

Fig. 1 ESEM micrographs of the cementitious matrix and ITZ around a PET- $\mathrm{H}_{2} \mathrm{O}$ fibre $(\mathrm{A}, \mathrm{C})$ and a PET-NaOH fibre (B,D).

abundance of hydroxyl groups on the surface (Machovič et al., 2008b). These changes lead to increasing fibre adhesion to the cementitious matrix during the hydration of the cement composite. This modifies the ITZ microstructure and increases strength of the bond between the fibre and cementitious matrix (Tagnit-Hamon et al., 2005).

The microstructure of ITZ between fibres and the cementitious matrix was studied using the environmental scanning electron microscopy (ESEM). Figure 1 shows micrographs of the studied cement composites obtained by the backscattered electron image analysis of polished sections of the concretes. It is obvious from the micrographs that in the composites containing the fibres treated by the alkaline hydrolysis with sodium hydroxide, ITZ is hardly noticeable, whereas the composites with the PET- $\mathrm{H}_{2} \mathrm{O}$ fibres have distinct heterogeneous ITZ with high pore content in the fibre vicinity. The transition zone extense up to 50 micrometers and contains a considerable amount of large pores with a high content of large crystals of calcium hydroxide. Also higher amounts of non-hydrated cementitious minerals occur in the ITZ area. Application of the $\mathrm{PET}-\mathrm{NaOH}$ fibres brought a significant decrease in the surface area of the cement composite from $19.54 \mathrm{~m}^{2} \mathrm{~g}^{-1}$ to $12.95 \mathrm{~m}^{2} \mathrm{~g}^{-1}$. This decrease in the surfaře area is connected with ITZ, where the pore volume in the PET-NaOH composite is lower than in the PET- $\mathrm{H}_{2} \mathrm{O}$ composite $\left(0.0433 \mathrm{ml} \mathrm{g}^{-1}\right.$ and $0.055 \mathrm{ml} \mathrm{g}^{-1}$, respectively). Porosity of both materials remained virtually unchanged $(30.4 \%$ and $31.2 \%$, respectively).

In the cement chemist notation $(\mathrm{CCN})$, the main oxides are abbreviated as follows: $\mathrm{C}=\mathrm{CaO}, \mathrm{S}=\mathrm{SiO}_{2}$, $\mathrm{H}=\mathrm{H}_{2} \mathrm{O}, \mathrm{A}=\mathrm{Al}_{2} \mathrm{O}_{3}, \mathrm{~F}=\mathrm{Fe}_{2} \mathrm{O}_{3}$. The cement hydration process can be represented by a set of chemical equations that describe the hydration of the main cement mineral phases with the following composition: $50-70 \%$ of tricalcium silicate (alite $\mathrm{C}_{3} \mathrm{~S}-\mathrm{Ca}_{3} \mathrm{SiO}_{5}$ ), 20-30\% of dicalcium silicate (belite, $\mathrm{C}_{2} \mathrm{~S}-\mathrm{Ca}_{2} \mathrm{SiO}_{4}$ ), 5-12\% tricalcium aluminate $\left(\mathrm{C}_{3} \mathrm{~A}-\mathrm{Ca}_{3} \mathrm{Al}_{2} \mathrm{O}_{6}\right)$, and $5-12 \%$ of calcium aluminoferrite $\left(\mathrm{C}_{4} \mathrm{AF}-\mathrm{Ca}_{4} \mathrm{Al}_{2} \mathrm{Fe}_{2} \mathrm{O}_{10}\right)$. Additional components such as gypsum are addends (ca. 2-5\%) (Ramachandran and Beaudoin, 2001). Hydration of the dry clinker leads to prevalence of the following composition: $20-25 \%$ of $\mathrm{Ca}(\mathrm{OH})_{2}$ (portlandite, $\mathrm{CH}$ ), $60-70 \%$ of $3 \mathrm{CaO} \cdot 2 \mathrm{SiO}_{2} \cdot 3 \mathrm{H}_{2} \mathrm{O}$ (calcium-silicatehydrate, C-S-H gel), and 5-15\% of other solid phases, e.g., ettringite $-\mathrm{Ca}_{6} \mathrm{Al}_{2}\left(\mathrm{SO}_{4}\right)_{3}(\mathrm{OH})_{12} \cdot 26 \mathrm{H}_{2} \mathrm{O}$. The $\mathrm{C}-\mathrm{S}-\mathrm{H}$ gel represents a primary binding phase in the Portland cement and controls strength development of the paste (Ramachandran and Beaudoin, 2001). 


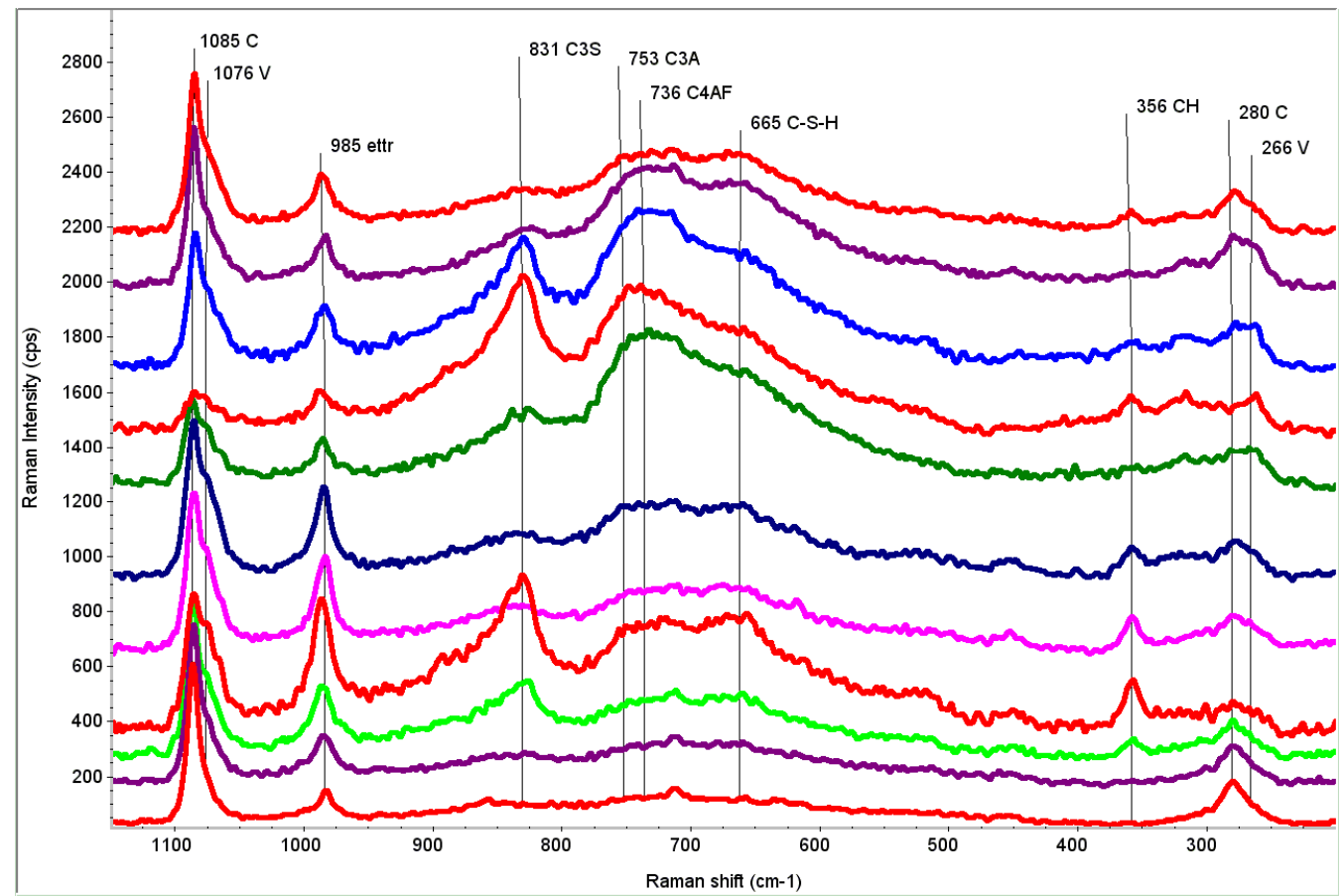

Fig. 2 Raman spectra of the cementitious matrix around a $\mathrm{PET} / \mathrm{H}_{2} \mathrm{O}$ fibre (from the bottom to the top: $0-100 \mu \mathrm{m}$, step $10 \mu \mathrm{m}, \mathrm{C}$ - calcite, $\mathrm{V}$ - vaterite, ettr - ettringite).

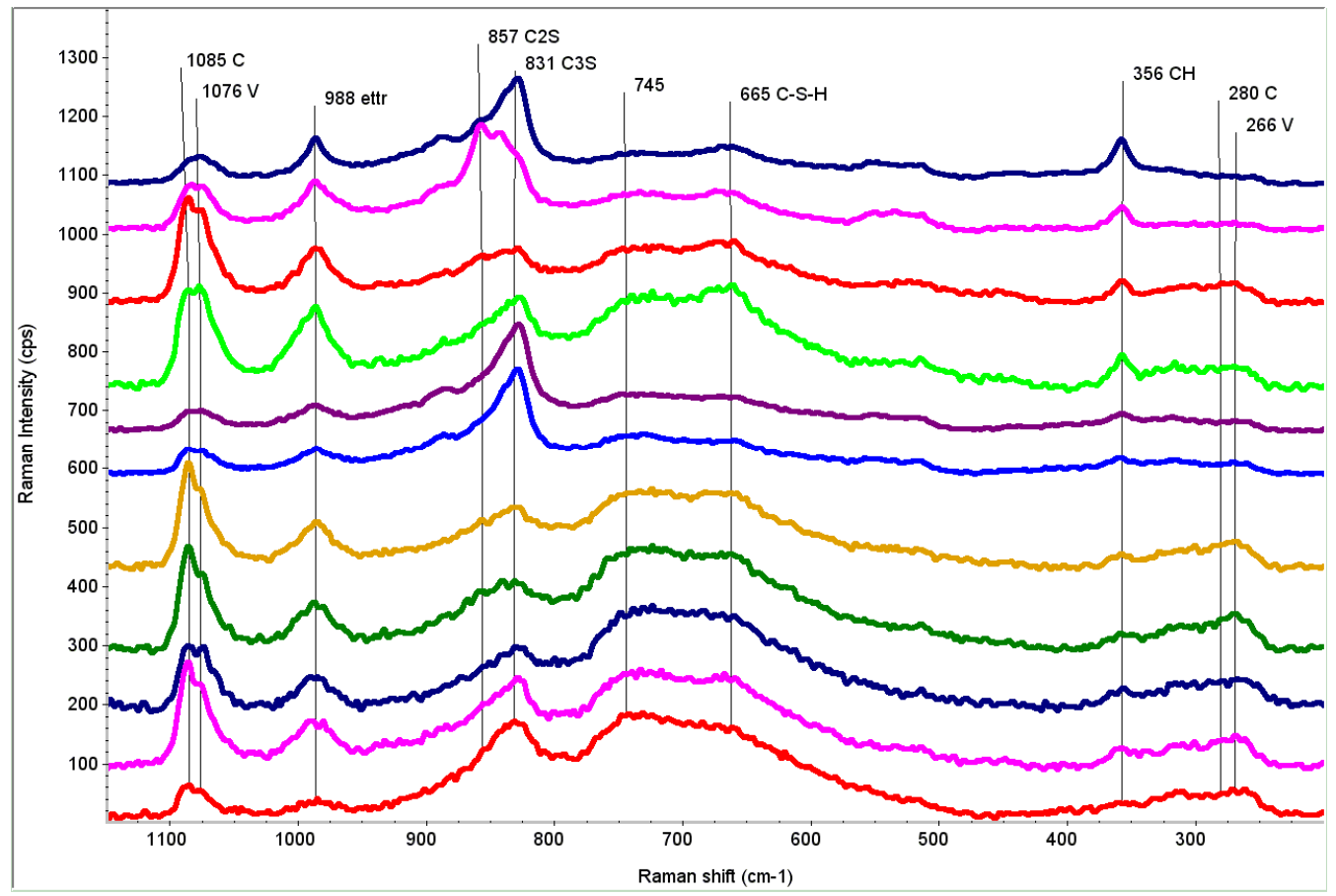

Fig. 3 Raman spectra of the cementitious matrix around a PET/NaOH fibre (from the bottom to the top: $0-100 \mu \mathrm{m}$, step $10 \mu \mathrm{m}, \mathrm{C}$ - calcite, $\mathrm{V}$ - vaterite, ettr - ettringite).

In Figures 2 and 3, Raman spectra of the cementitious matrix are presented, measured from the surface of alkaline non-treated and treated fibres, up to a 100 micrometer distance with a 10 micrometer step. The line Raman spectroscopy mapping was carried out on perfectly smooth polished sections of the studied composites. Within the spectral region $900-$
$780 \mathrm{~cm}^{-1}$, bands of two main cement minerals with incomplete hydravion can be found. The band at $831 \mathrm{~cm}^{-1}$ belongs to the symmetric stretching vibration of $\mathrm{SiO}_{4}{ }^{4-}$ in alite $\left(\mathrm{Ca}_{3} \mathrm{SiO}_{5}\right)$, and the belite $\left(\mathrm{Ca}_{2} \mathrm{SiO}_{4}\right)$ band has a peak at $858 \mathrm{~cm}^{-1}$. From a comparison of intensities of the band at $831 \mathrm{~cm}^{-1}$ it can be observed that alite is present locally in individual larger grains, 


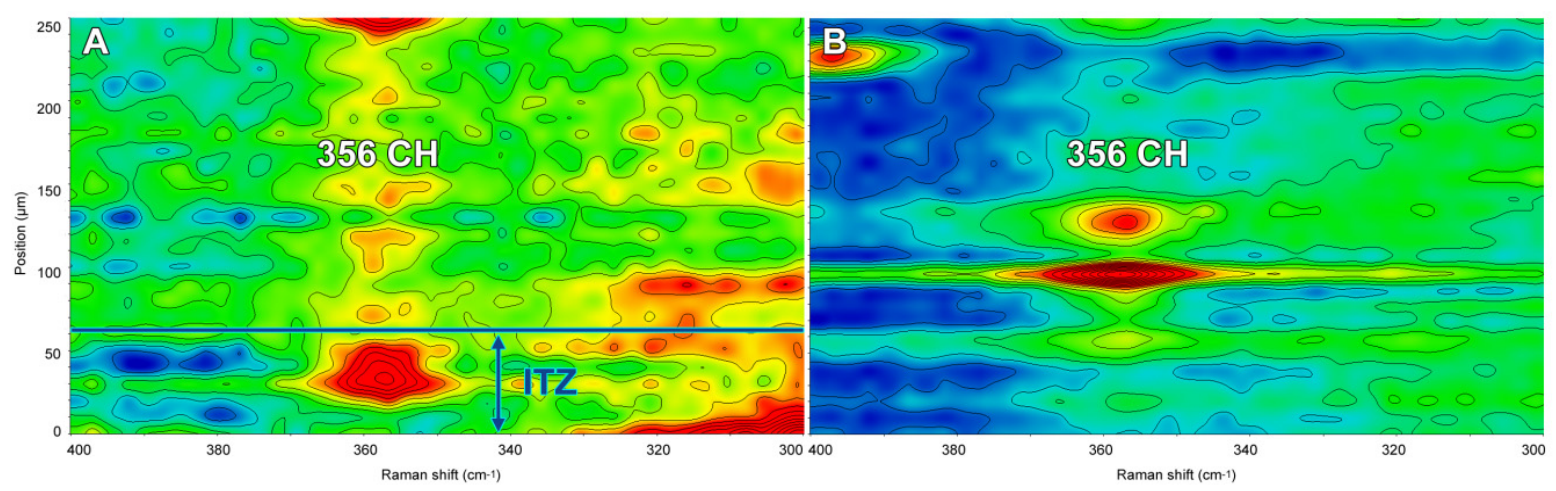

Fig. 4 2D contour maps of Raman spectral intensities $\left(400-300 \mathrm{~cm}^{-1}\right)$ in the cementitious matrix in the vicinity of a PET- $\mathrm{H}_{2} \mathrm{O}$ fibre (A) and a PET-NaOH fibre (B).

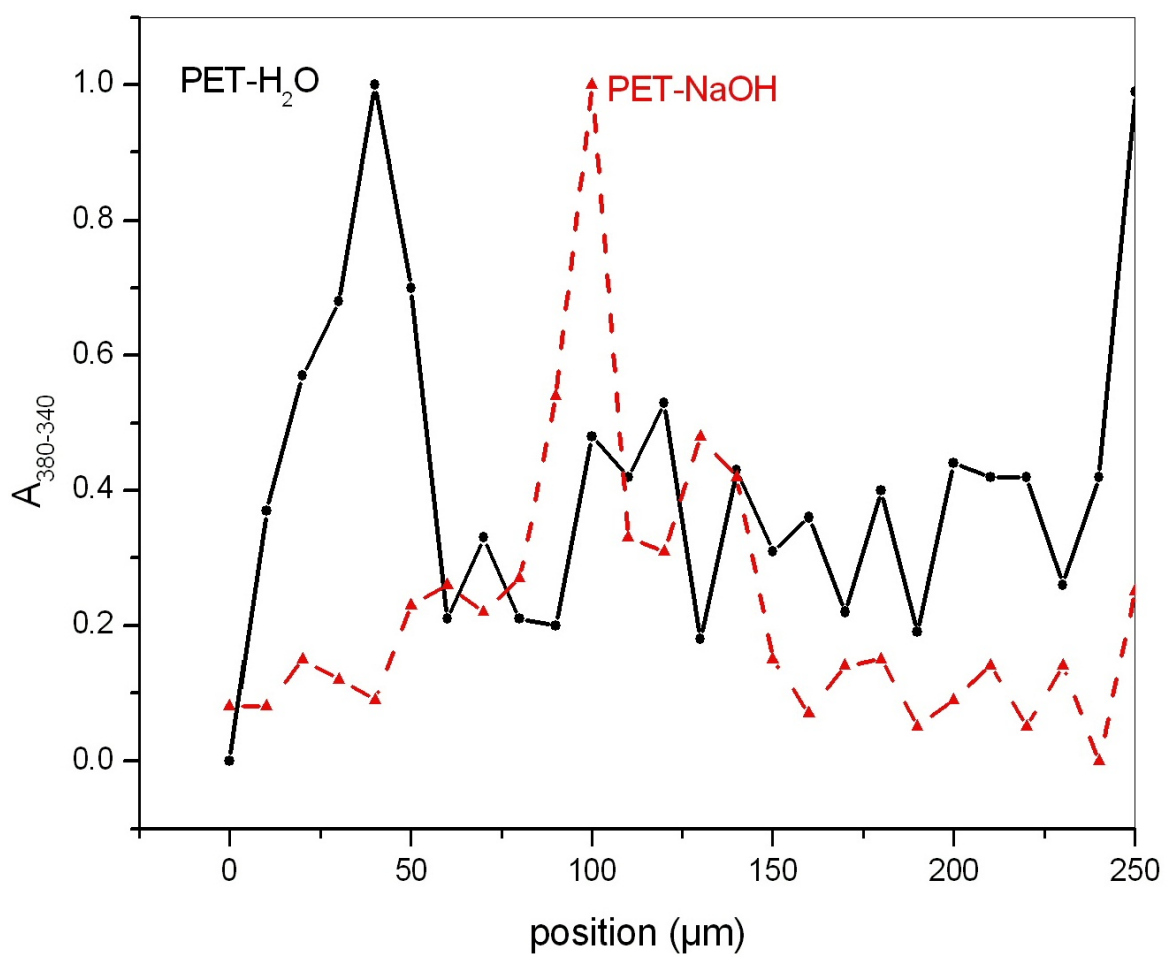

Fig. 5 Profile of the portlandite band area around hydrolysed and non-hydrolysed PET fibres.

as it is obvious also in the ESEM micrograph in Figure 1. A broad feature near $730 \mathrm{~cm}^{-1}$ is composed of vibrations of $\mathrm{C}_{4} \mathrm{AF}$ and $\mathrm{C}_{3} \mathrm{~A}$ at $737 \mathrm{~cm}^{-1}$ and $754 \mathrm{~cm}^{-1}$, respectively (Deng et al., 2002).

Calcium hydroxide, ettringite, and the C-S-H gel are the main hydration products of cement. For mapping of the presence of calcium hydroxide within the distance $0-250$ micrometers from a PET- $\mathrm{H}_{2} \mathrm{O}$ fibre, the band area of bending vibration of $\mathrm{Ca}-\mathrm{O}$ bonds in the $380-340 \mathrm{~cm}^{-1}$ region, with a maximum at $356 \mathrm{~cm}^{-1}$, was used. The relative abundance of $\mathrm{CH}$ for both fibre types in the cementitious matrix is shown in the 2D contour maps in Figure 4. It is obvious from the $2 \mathrm{D}$ contour maps that the highest relative abundance of $\mathrm{CH}$ can be found within the distance $0-50$ micrometers from a non-hydrolysed fibre. The maps have been supplemented by a concentration profile of portlandite (Fig. 5) constructed by integration of the band of portlandite at $356 \mathrm{~cm}^{-1}$, as a function of the distance from the surface of a fibre. It can be clearly observed in both graphs that the $\mathrm{CH}$ concentration around the fibres is much higher in the cementitious matrix with the $\mathrm{PET}-\mathrm{H}_{2} \mathrm{O}$ fibres than in the matrix with the PET-NaOH fibres. These results correspond with the results of electron microscopy, where large $\mathrm{CH}$ crystals within the porous ITZ around a $\mathrm{PET}-\mathrm{H}_{2} \mathrm{O}$ fibre are visible. 


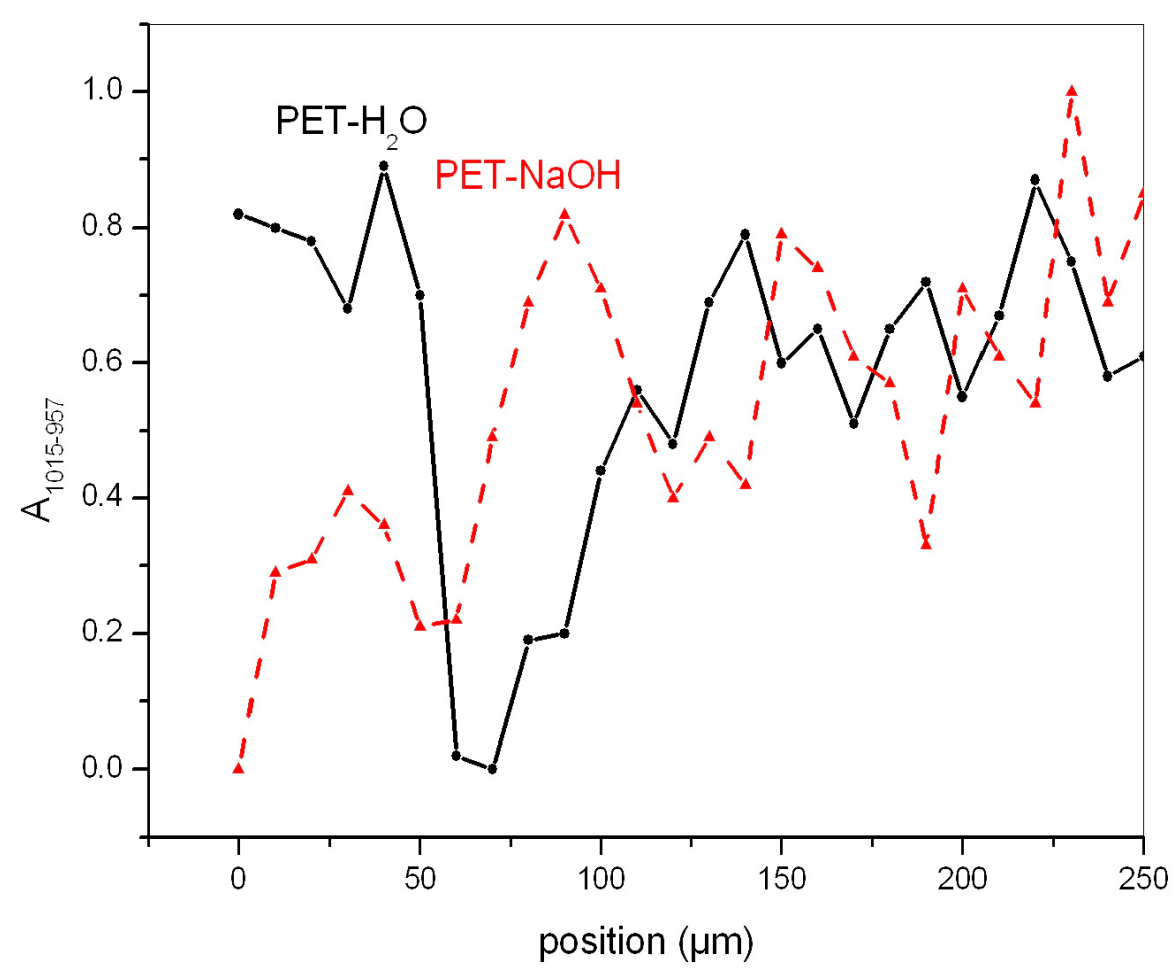

Fig. 6 Profile of the ettringite band area around hydrolysed and non-hydrolysed PET fibres.

The band of symmetric stretching vibrations of $\mathrm{SO}_{4}{ }^{2-}$ in ettringite can be found at $987 \mathrm{~cm}^{-1}$. In some spots measured the band is asymmetric, possibly due to the presence of other sulphates. Concentration profiles of ettringite in the cement paste (Fig. 6) have character similar to that of calcium hydroxide for both fibre types, and a higher content of needle shaped ettringite crystals in the ITZ around the unmodified fibres can be expected.

The spectrum of $\mathrm{C}-\mathrm{S}-\mathrm{H}$ shows a broad symmetric stretching motion of the $\mathrm{Si}-\mathrm{O}-\mathrm{Si}$ bending mode near $665 \mathrm{~cm}^{-1}$, due to poor crystallinity of $\mathrm{C}-\mathrm{S}-\mathrm{H}$. Redistribution of the $\mathrm{C}-\mathrm{S}-\mathrm{H}$ gel is not much distinct due to a lower mobility of silicate ions (Ollivier, et al., 1995).

Via the reaction of atmospheric $\mathrm{CO}_{2}$ with $\mathrm{Ca}^{2+}$ ions in aqueous solutions inside pores, carbonation of mortars and concretes significantly changes their properties as porosity and mechanical strength. Besides calcite as the main product, other $\mathrm{CaCO}_{3}$ polymorphs as aragonite and vaterite are formed. Calcite is the thermodynamically most stable polymorph of $\mathrm{CaCO}_{3}$ (Martinez-Ramirez et al., 2003). The main bands of calcite and vaterite are marked in the spectra depicted in Figures 2 and 3. Based on comparison of the band intensities, it can be concluded that the composite containing the PET$\mathrm{NaOH}$ fibres is characterized by a higher vaterite/calcite ratio than the composite with the PET$\mathrm{H}_{2} \mathrm{O}$ fibres.
Raman microspectroscopy mapping seems to be a suitable auxiliary tool to electron microscopy for observing changes in the content of various mineral phases as portlandite, ettringite, carbonate, and original clinker minerals within the ITZ area between fibres or stone aggregates, as well as in the more distant cementitious matrix. Future research should focus on investigation of mechanical properties of the PET fibre reinforced concretes using physical and mechanical tests, such as measurements of compressive and flexural strength, elasticity modulus, and flexural toughness.

\section{CONCLUSIONS}

The microstructure of ITZ between fibres produced from waste PET bottles and Portland cementitious matrix was studied. Due to poor adhesion and wettability of PET fibres, they were treated by alkaline hydrolysis at an elevated temperature. This modification increased the fibre surface and the content of polar groups, and was followed by changes in the ITZ microstructure and interfacial bond between fibre and the cement paste. Electron microscopy (ESEM) has shown that the composites containing PET fibres treated by $\mathrm{NaOH}$ hydrolysis have almost invisible ITZ, whereas the composites with non-hydrolysed PET fibres have distinct heterogeneous ITZ with a thickness up to $50 \mu \mathrm{m}$ and high abundance of large pores containing large crystals of portlandite and ettringite. 
Raman microspectroscopy was employed to study changes in the content of mineral phases in the cementitious matrix within the $0-250 \mu \mathrm{m}$ distance from a PET fibre. The band at $357 \mathrm{~cm}^{-1}$ corresponding to vibration of the $\mathrm{Ca}-\mathrm{O}$ band in $\mathrm{Ca}(\mathrm{OH})_{2}$ was used to determine the $\mathrm{Ca}(\mathrm{OH})_{2}$ distribution. The relative abundance of ettringite was determined from the band of $\mathrm{SO}_{4}{ }^{2-}$ stretching vibrations at $987 \mathrm{~cm}^{-1}$. The most intensive bands of portlandite and ettringite were observed within a $50 \mu \mathrm{m}$ distance from a nonhydrolysed PET fibre. The cement composites prepared with the alkaline hydrolysed PET fibres do not have an increased concentration of the above mineral phases near the fibre surface.

\section{ACKNOWLEDGEMENT}

This work has been supported by the grant No. P104/10/2344 of the Czech Science Foundation and by the Grant Agency of the Czech Technical University in Prague, grant No. SGS12/116/OHK1/2T/11

\section{REFERENCES}

Chan, Y-W. and Li, V.C.:1997, Effects of transition zone densification on fibre/cement paste bond strength improvement, Advanced Cement Based Materials, 5, No. 1, 8-17. DOI: 10.1016/S1065-7355(96)00077-6

Deng, C.S., Breen, C., Yarwood, J., Habesch, S., Phipps, J., Craster, R. and Maitland, G.: 2002, Ageing of oilfield cement at high humidity: a combined FEG-ESEM and Raman microscopic investigation, Journal of Materials Chemistry, 11, No. 10, 3105-3112. DOI: $10.1039 / \mathrm{b} 203127 \mathrm{~m}$

Gastaldi, D., Boccaleri, E., Canonico, F. and Bianchi, M.: 2007, The use of Raman spectroscopy as a versatile characterization tool for calcium sulphoaluminate cements: a compositional and hydration study, Journal of Materials Science, 42, No. 20, 8426-8432. DOI: $10.1007 / \mathrm{s} 10853-007-1790-8$

Machovič, V., Kopecký, L., Němeček, J., Kolář, F., Svítilová, J., Bittnar, Z. and Andertová, J.: 2008a, Raman microspectroscopy mapping and microstructural and micromechanical study of interfacial transition zone in concrete reinforced by polyethylene terephthalate fibres, Ceramics-Silikáty 52, No. 1, 54-60.

Machovič, V., Andertová, J., Kopecký, L., Černý, M., Borecká, L., Přibyl, O., Koláŕ, F. and Svítilová, J.: 2008 b, Effect of aging of PET fibre on the mechanical properties of PET fibre reinforced cement composite, Ceramics-Silikáty, 52, No. 3, 172-182.
Martinez-Ramirez, S., Sanchez-Cortez, S.S., Garcia-Ramos, J.V., Domingo, C., Fortes, C. and Blanco-Varela, M.T.: 2003, Micro-Raman spectroscopy applied to depth profiles of carbonates formed in lime mortar, Cement and Concrete Research, 33, No. 12, 20632068. DOI: 10.1016/s0008-8846(03)00227-8

Ollivier, P., Maso, J.C. and Bourdette, B.: 1995, Interfacial transition zone in concrete, Advanced Cement Based Materials, 2, No. 1, 30-38. DOI: 10.1016/1065-7355(94)00021-5

Pešková, Š., Machovič, V. and Procházka, P.: 2011 Raman spectroscopy structural study of fired concrete, Ceramics - Silikáty, 55, No. 4, 410-417.

Potgieter-Vermaak, S.S., Potgieter, J.H. and Van Grieken, R.: 2006, The application of Raman spectrometry to investigate and characterize cement, Part I: A review, Cement and Concrete Research, 36, No. 4, 656-662. DOI: 10.1016/j.cemconres.2005.09.008

Ramachandran, V.S. and Beaudoin, J.J.: Handbook of analytical techniques in concrete science and technology, Principles, Techniques, and Applications, William Andrew Publishing/Noyes Publications, Norwich, New York 2001.

Scrivener, K.L.: 2004, Backscattered electron imaging of cementitious microstructures: understanding and quantification, Cement and Concrete Composites, 26, No. 8, 935-945. DOI: 10.1016/j.cemconcomp.2004.02.029

Scrivener, K., Crumbie, A.K. and Laugesen, P.: 2004, The Interfacial Transition Zone (ITZ) between cement paste and aggregate in concrete, Interface Science, 12, No. 4, 411-421. DOI: 10.1023/B:INTS.0000042339.92990.4c

Tagnit-Hamou, A., Vanhove, Y. and Petrov, N.: 2005, Microstructural analysis of the bond mechanism between polyolefin fibres and cement pastes, Cement and Concrete Research, 35, No. 2, 367-370. DOI: 10.1016/j.cemconres.2005.05.046

Zollo, R.F.: 1997, Fibre-reinforced Concrete: an Overview after 30 Years of Development, Cement and Concrete Composites, 19, No. 2, 107-122. DOI: 10.1016/S0958-9465(96)00046-7 